\title{
Impact of Blood Loss on Outcome after Liver Resection
}

\author{
Marieke T. de Boer I. Quintus Molenaar Robert J. Porte \\ Department of Surgery, Section Hepatobiliary Surgery and Liver Transplantation, University Medical Center \\ Groningen, University of Groningen, Groningen, The Netherlands
}

\begin{abstract}
Key Words
Blood transfusions in liver surgery, evolution · Blood transfusion, immunosuppressive effect • Blood loss • Blood transfusion · Colorectal metastases $\cdot$ Hepatocellular carcinoma $\cdot$ Cholangiocarcinoma
\end{abstract}

\begin{abstract}
Partial liver resections are the treatment of choice for patients with a malignant liver or bile duct tumor. The most frequent indications for partial liver resections are colorectal metastasis, hepatocellular carcinoma (HCC) and cholangiocarcinoma. Liver resection is the only therapy with a chance for cure in these patients. Refinements in surgical technique and increasing experience have contributed to a reduction in perioperative morbidity and mortality in recent years. Despite these improvements, partial liver resections remain a major surgical procedure and carry the risk for excessive blood loss and a subsequent need for blood transfusion. Blood transfusions have been associated with systemic side effects, such as depression of the immune system. Several studies have suggested that perioperative blood loss or transfusions have a negative impact on postoperative outcome. However, it has been debated whether this is due to a real cause-effect relationship or merely the result of more complicated surgery. We have reviewed the literature concerning studies focusing on the relationship between blood loss and blood transfusion during liver surgery for malignant tumors and postoperative outcome. Most studies were based on a retrospective analysis of single center experienc-
\end{abstract}

es, using uni- and multivariate statistical methods. Most studies have demonstrated a significant and clinically relevant association between blood transfusion and postoperative mortality and morbidity, especially postoperative infectious complications. The effect of blood transfusions on tumor recurrence and more long-term mortality is much less clear and evidence varies depending on the type of malignancy. The strongest indication that blood transfusion may have an impact on tumor recurrence has been found for patients with early stages of HCC. However, overall, no such effect could be demonstrated for patients undergoing partial liver resection for late stages of HCC, colorectal liver metastasis or cholangiocarcinoma.

Copyright $\odot 2007$ S. Karger AG, Base

\section{Introduction}

Liver resection has been accepted as the standard treatment for most benign and malignant liver tumors. True anatomical right hepatectomy was first described by Lortat-Jacobs and Robert [1] in 1952. The subsequent early experience with hepatic resection has been discouraging, showing mortality figures over $20 \%$ for major hepatectomies in a retrospective series of 621 patients operated for a variety of indications [2]. In $20 \%$ of these patients, death was attributed to hemorrhage [2].

Evolution of surgical and anesthetic techniques, better understanding of the segmental liver anatomy, new methods to control hemorrhage, and better patient selection

\section{KARGER}

Fax +4161306 1234

E-Mail karger@karger.ch

www.karger.com
(C) 2007 S. Karger AG, Basel

$0253-4886 / 07 / 0244-0259 \$ 23.50 / 0$

Accessible online at:

www.karger.com/dsu
Robert J. Porte, MD, PhD

Hepatobiliary Surgery and Liver Transplantation

University Medical Center Groningen, PO Box 30.001

NL-9700 RB Groningen (The Netherlands)

Tel. +31 50361 2896, Fax +31 50361 4873, E-Mail r.j.porte@chir.umcg.nl 
have led to improvement in outcome. Nowadays, liver resections are performed in specialized centers with a perioperative mortality rate of less than $5 \%$ even though the indications for liver resections have been extended, also to high-risk patients [3-9]. In a consecutive series of 1,222 liver resections, Poon et al. [3] have described a gradual reduction in transfused patients from around $90 \%$ in 1989 to 5\% in 2003. Despite these improvements, blood loss remains one of the main predictors of both perioperative morbidity and mortality after liver resection [7, 10]. The possible negative sequelae of blood transfusions are well known and include alloimmunization [11-16], transmission of viral diseases [17], graft-versus-host disease [18], increased postoperative infection rate [16, 1921], and increased incidence of tumor recurrence in certain cancers [16, 22-27].

In this paper an overview is given on the impact of blood loss and blood transfusion on outcome after liver resections for the most prevalent malignant tumors of the liver: colorectal metastasis, hepatocellular carcinoma (HCC) and cholangiocarcinoma.

\section{Evolution of Blood Transfusions in Liver Surgery}

The hypothesis that transfusion compromises outcome after liver resection has both been supported and refuted in various studies. Limitations of older studies were the small sample sizes but also the low numbers of non-transfused patients $[28,29]$. More recent studies with larger numbers of both transfused and non-transfused patients have been able to confirm the detrimental effects of transfusion on the development of postoperative complications $[3,7,8,10]$ and perioperative death after liver resections [7, 10]. Poon et al. [3] have described a series of 1,222 consecutive liver resections for benign and malignant lesions between 1989 and 2003. In this time period a doubling of the number of resections was observed between the first (group 1: 1989-1996) and last half (group 2: 1996-2003) as a result of more liberal patient selection, leading to significantly more elderly patients, patients with more comorbidity and significantly worse preoperative liver function. Despite this, the intraoperative blood loss and transfusion requirements, as well as postoperative morbidity and hospital mortality, were significantly lower in group 2, compared to group 1. Transfusion of blood products was one of the independent predictors of morbidity identified in a multivariate analysis [3]. Another large retrospective study on the improvement of outcome after liver resections has been reported by Jarnagin et al. [7]. This group has described a consecutive series of 1,803 liver resections for both benign and malignant lesions performed between 1992 and 2001. Over the years, an increase in concomitant major procedures was observed, but operative mortality decreased from approximately $4 \%$ in the first 5 years of the study to $1.3 \%$ in the last 2 years. In a multivariate analysis, the number of hepatic segments resected and operative blood loss were the only independent predictors of both perioperative morbidity and mortality [7].

\section{Immunosuppressive Effect of Blood Transfusion}

The possibility to store and transfuse blood has been a major advance in medicine in the 20th century, saving countless lives. One of the side effects of blood transfusion, however, is immunosuppression, which is assumed to cause decreased tumor surveillance and worse outcome $[11,16,20]$. In different fields of cancer surgery these negative effects have been examined, but also disputed. Even though the percentage of patients receiving blood transfusion has decreased [3], blood loss remains a major concern in liver surgery [6,30-33]. The mechanisms underlying the adverse effects of blood product transfusions with respect to postoperative outcome have been assumed to be related to the suppressive effects on the immune system. Although the exact mechanism of this is not fully understood, several studies have suggested that blood transfusions suppress host immunity via a reduction in natural killer cell function, decreased cytotoxic T-cell function, increased numbers of suppressor T cells and decreased function of macrophages and monocytes $[12,13,16]$. Many of these immunosuppressive effects are thought to be related to the number of leukocytes within the stored blood as well as to the length of blood storage [34]. Theoretically these immunosuppressive effects should be less in leukocyte-depleted blood transfusion, which is standard nowadays in most western countries $[35,36]$. More and larger studies will be needed to confirm this assumed benefit of leukocyte depletion.

\section{Effects of Blood Loss and Blood Transfusion in Colorectal Metastases}

Only few studies have focused on the effect of blood transfusions on outcome after partial liver resections for colorectal metastasis. Kooby et al. [10] have retrospectively described a series of 1,351 patients who were treat- 
ed for colorectal liver metastases between 1986 and 2001. A total of $55 \%$ of these patients received some blood product transfusion (red blood cell, fresh-frozen plasma, or platelet concentrate transfusion), $6 \%$ received autologous blood and $39 \%$ of the patients did not receive any transfusion. The percentage of patients transfused reduced markedly over time. Non-transfused patients had significantly fewer complications than patients who needed blood transfusions ( 33 vs. $46 \%, p<0.001$ ). This effect was dose-related. Patients transfused with autologous blood had complication rates similar to patients receiving one or two allogeneic transfusions. Patients who received autologous blood transfusions had significantly more complications than patients who did not require transfusions. In a multivariate analysis, independent predictors of postoperative complications were blood transfusion (OR $1.5 ; \mathrm{p}=0.0008)$, extent of the resection (OR 2.0; $\mathrm{p} \leq$ $0.0001)$ and male gender (OR 1.4; $\mathrm{p}=0.002)$. In addition, blood transfusion was found to be a predictor for postoperative mortality on multivariate analysis (HR 3.7; 95\% CI 1.7-8.4; $\mathrm{p}=0.001$ ) together with the extent of the resection (HR 4.9; 95\% CI 1.8-13.8; $\mathrm{p}=0.003$ ). Blood transfusion, however, was not a significant predictor of longterm survival [10].

In another retrospective study, Stephenson et al. [28] have also analyzed the effect of blood transfusion on tumor recurrence in series of 55 consecutive patients who underwent partial liver resection for colorectal metastasis. In this study, an increase in number of units of blood transfused was found to be associated with a decreased time to recurrence in a Cox proportional hazards model analysis (RR 1.05; $p=0.0015)$ [28]. In contrast with these studies suggesting a relationship between blood transfusions and tumor recurrence after partial hepatectomy for colorectal metastasis, Younes et al. [29] were not able to identify blood transfusion as in independent risk factor for tumor recurrence in a group of 116 patients. Although a significant association between blood transfusion and tumor recurrence was found in univariate analysis, this could not be confirmed as an independent predictor in multivariate analysis. These investigators found hypotensive episodes during surgery, the site of the primary tumor, level of serum CEA, and the number of metastases as the only significant independent predictors of tumor recurrence [29]. Altogether, there is no convincing scientific support for an effect of perioperative blood transfusions on the risk of tumor recurrence after partial liver resection of colorectal liver metastases.

\section{Effects of Blood Loss and Blood Transfusion in HCC}

HCC is mainly found in cirrhotic livers and most studies focusing on this type of malignancy have focused on partial liver resection in cirrhotic patients. In a series of 155 patients undergoing extended hemihepatectomy for HCC, Wei et al. [21] have analyzed risk factors for perioperative morbidity and mortality. The overall morbidity rate in this series was $55.5 \%$ and mortality rate was $8.4 \%$. These investigators were able to identify perioperative blood transfusion $(\mathrm{p}<0.001)$ and portal clamping during the resection $(\mathrm{p}=0.023)$ as independent risk factors for postoperative morbidity. Independent risk factors for perioperative mortality were perioperative blood transfusion $(\mathrm{p}=0.004)$ and comorbid illness $(\mathrm{p}=0.019)$ [21]. Outcome after partial hepatectomy for HCC has also studied by Fan et al. [5] in a large retrospective analysis of 330 patients operated between 1989 and 1997 in a single institution in Hong Kong. These investigators have reported a zero mortality rate in their series. There were no significant changes in the patient characteristics throughout the 9-year time period, but a significant reduction in intraoperative blood loss and blood transfusion requirements was observed in this time period. In the most recent years of this analysis, the median blood transfusion requirement was $0 \mathrm{ml}$, and $64 \%$ of the patients did not require any blood transfusion. In a univariate analysis, the volume of blood loss, volume of blood transfusions, and operation time correlated significantly with postoperative morbidity rates in the most recent two years (1996 and 1997). In a multivariate stepwise logistic regression analysis, operation time could be identified as the only parameter that correlated significantly with the postoperative morbidity rate [5].

The effects of blood transfusion on recurrence in HCC after partial hepatectomies, has been studied in several series [22, 37-40]. Asahara et al. [22] have described 175 patients who underwent a partial liver resection for HCC between 1986 and 1994. The cumulative cancer-free survival rate for patients who had received blood transfusion ( $\mathrm{n}=$ 23) was significantly lower than that for patients who had not received blood transfusions $(\mathrm{n}=152)(\mathrm{p}=0.003)$. Multivariate analysis for risk factors for recurrence in stage I and II of HCC showed significance for blood transfusion $(\mathrm{p}=0.006)$, extent of resection ( $\mathrm{p}=0.04)$, and ICG clearance $(\mathrm{p}=0.04)$. No significant effect of blood transfusion was observed on cancer-free survival rates in patients with HCC in stage III-IV. Also, no significant relation between blood transfusion and the degree of liver cirrhosis was found in this analysis. In another study of 252 patients undergoing partial liver resection for HCC, the incidence of 
tumor recurrence was found to be significantly higher in a subgroup of patients who had HCC without angioinvasion and had received intraoperative blood transfusion [37]. These studies suggest that the impact of blood transfusions on tumor recurrence is most pronounced in patients with relatively early stages of HCC. These observations are in line with studies suggesting that immune surveillance is oncologically more relevant in early stages than in the more advanced stages of HCC $[22,37]$.

\section{Effects of Blood Loss and Blood Transfusion in Cholangiocarcinoma}

Very few studies have focused on the impact of blood transfusions on outcome after partial liver resections for cholangiocarcinoma. Nagino et al. [41] have reported a series of 100 consecutive patients undergoing combined resections of extrahepatic bile ducts and part of the liver for hilar cholangiocarcinoma. Preoperative blood donation was performed in 73 patients in this series. Only 7 of these 73 patients (10\%) required allogeneic blood transfusions. In the remaining 27 patients, 18 (67\%) received allogeneic blood transfusion during surgery. During the postoperative period, 16 patients needed a blood transfusion. The incidence of postoperative complications was significantly higher in the 35 patients who received a perioperative blood transfusion than in the 65 patients who did not ( 94 vs. $52 \%$; $\mathrm{p}<0.0001$ ). No multivariate analysis was done to identify independent risk factors [41].

In a recent publication by Liu et al. [42], a group of 142 patients is described with hilar cholangiocarcinoma in the period 1989-2004. For comparison of outcome, patients were divided between two groups: period 1, 19891998, and period 2, 1999-2004. Modifications in management resulted in a higher resection rate in period 2 than in period 1 (45 vs. 16\%). In multivariate analysis, resection of the tumor in period 2 and operative blood loss of 1.51 or less were significant independent determinants of improved overall survival [42].

There are no data on the effects of blood transfusion on long-term survival or tumor recurrence after partial liver resection for cholangiocarcinoma.

\section{Conclusions and Perspectives for the Future}

Recent improvements in the surgical techniques used for hepatic resections as well as optimal intra- and postoperative patient management have led to a significant improvement in short- and long-term outcome in patients undergoing partial liver resections [3-10]. Blood transfusions have been identified as an independent predictor of postoperative morbidity and mortality. Unfortunately, many patients will get recurrent disease, even after complete oncological resection. The impact of blood transfusions on the risk for tumor recurrence has best been characterized for patients with early stages of HCC $[22,37]$. Much less evidence exists with respect to the effect of blood transfusion on the risk of tumor recurrence after resections for colorectal liver metastases [28, 29]. A similar adverse effect of blood transfusion on tumor recurrence has been reported for gastric cancer [23], colon cancer [24, 25], lung cancer [26] and soft tissue carcinoma [27]. The main problem with all these studies remains their retrospective design, which never allows complete ruling out of the possibility that blood transfusion and outcome are affected by a common underlying cause, such as more advanced disease, or more complex surgery. Nevertheless, investigators have tried to overcome these limitations by performing multivariate regression analyses, including variables that reflect severity of disease.

Although the exact mechanisms underlying the adverse effects of blood transfusions are not fully elucidated, residual amounts of donor leukocytes present in transfusions as well as preservation-related changes in erythrocytes are assumed to be critically involved [34$36,43,44]$. Whether the increasing use of leukoreduction technologies will lead to a reduction of the negative impact of blood transfusion on outcome after liver resections needs to be awaited and requires additional studies. Future studies on blood loss and transfusion in liver surgery should focus on methods to further reduce blood loss and the need for allogeneic blood transfusion. Strategies to minimize the risks of allogeneic blood transfusion are leukocyte-depleted transfusions, short storage time and the use of autologous blood transfusion. Methods for autologous transfusion used in liver surgery include preoperative blood donation [19, 45-47], intraoperative acute normovolemic hemodilution [48], and intraoperative blood salvage $[49,50]$. However, these methods are not common clinical practice yet because of logistical reasons in preoperative blood donation or the required training of the operating team in intraoperative hemodilution. Furthermore, intraoperative blood salvage theoretically increases the risk of tumor cell dissemination.

In conclusion, the effects of blood loss and blood transfusions in liver surgery have been studied extensively. Most studies have demonstrated a significant and clini- 
cally relevant association between blood transfusion and postoperative morbidity, especially postoperative infectious complications. The effect of blood transfusions on tumor recurrence and more long-term mortality is much less clear and evidence varies depending on the indication for liver resection and the type of malignancy. The strongest indication that blood transfusion may have an impact on tumor recurrence has been found for patients with early stages of HCC, but no such effect could be demonstrated for patients undergoing partial liver resection for late stages of HCC, colorectal liver metastasis or cholangiocarcinoma.

\section{References}

1 Lortat-Jacobs J, Robert H: Hépatectomie droite réglée. Presse Méd 1952;60:549-551.

- 2 Foster JH, Berman MM: Solid liver tumors. Major Probl Clin Surg 1977;22:1-342.

3 Poon RT, Fan ST, Lo CM, Liu CL, Lam CM, Yeun WK, Yueng C, Wong J: Improving perioperative outcome expands the role of hepatectomy in management of benign and malignant hepatobiliary diseases. Analysis of 1,222 consecutive patients from a prospective database. Ann Surg 2004;240:698-710.

4 Fortner JG, MacLean BJ, Kim DK, et al: The seventies evolution in liver surgery for cancer. Cancer 1981;47:2162-2166.

5 Fan ST, Lo CM, Liu CL, Lam CM, Yuen WK, Yeung C, Wong J: Hepatectomy for hepatocellular carcinoma: toward zero hospital deaths. Ann Surg 1999;229:322-330.

6 Belghiti J, Hiramatsu K, Benoist S, et al: Seven hundred fifty-six hepatectomies in the 1990s: an update to evaluate the actual risk of liver resection. J Am Coll Surg 2000;191: $38-46$.

7 Jarnagin WR, Gonen M, Fong Y, Dematteo RP, Ben-Porat L, Little S, Corvera C, Weber $S$, Blumgart L: Improvement in perioperative outcome after hepatic resection. Analysis of 1803 consecutive cases over the past decade. Ann Surg 2002;236:397-407.

8 Imamura H, Seyama Y, Kokudo N, et al: One thousand fifty-six hepatectomies without mortality in 8 years. Arch Surg 2003; 138: 1198-1206.

$\checkmark 9$ Heriot AG, Karanjia ND: A review of techniques for liver resection. Ann R Coll Surg Engl 2002;84:371-380.

10 Kooby DA, Stockman J, Ben-Porat L, Gonen M, Jarnagin WR, Dematteo RP, Tuorto S, Wuest D, Blumgart LH, Fong Y: Influence of transfusion on perioperative and long-term outcome in patients following hepatic resection for colorectal metastases. Ann Surg 2003;237:860-870.

11 Opelz G, Terasaki PI: Prolongation effect of blood transfusions on kidney graft survival. Transplantation 1976;22:380-383.

$\checkmark 12$ Gascon P, Zoumbos NC, Young NS: Immunological abnormalities in patients receiving multiple blood transfusions. Ann Intern Med 1984;100:173-177.
13 Kaplan J, Sarnaik S, Gitlin J, et al: Diminished helper/suppressor lymphocyte ratios and natural killer activity in recipients of repeated blood transfusions. Blood 1984;64: 308-310.

14 Keown PA, Descamps B: Improved renal allograft survival after blood transfusion: a nonspecific, erythrocyte-mediated immunoregulatory process? Lancet 1979;i:20-22.

15 Kwon AH, Matsui Y, Kamiyama Y: Perioperative blood transfusion in hepatocellular carcinomas: influence of immunological profile and recurrence free survival. Cancer 2001;91:771-778.

16 Blumberg N, Heal JM: Effects of transfusion on immune function. Cancer recurrence and infection. Arch Pathol Lab Med 1994;118: 371-379.

17 Peterman TA, Jaffe HW, Feorino PM, Getchell JP, Warfield DT, Haverk HW, et al: Transfusion-associated acquired immunodeficiency syndromes in the United States. JAMA 1985;254:2913-2917.

-18 Arsura EL, Bertelle A, Minkowitz S, Cunningham JN, Grob D: Transfusion-associated graft-versus-host disease in a presumed immunocompetent patient. Arch Intern Med 1988;148:1941-1944.

19 Shinozuka N, Koyama I, Arai T, Numajiri Y, Watanabe T, Nagashima N, et al: Autologous blood transfusion in patients with hepatocellular carcinoma undergoing hepatectomy. Am J Surg 2000;179:42-45.

20 Triulzi DJ, Vanek K, Ryan DH, Blumberg N: A clinical and immunologic study of blood transfusion and postoperative bacterial infection in spinal surgery. Transfusion 1992; 32:517-524.

21 Wei AC, Tung-Ping Poon R, Fan ST, Wong J: Risk factors for perioperative morbidity ad mortality after extended hepatectomy for hepatocellular carcinoma. Br J Surg 2003;90: 33-41.

22 Asahara T, Katayama K, Itamoto T, Yano M, Hino H, Okamoto Y, Nakahara H, Dohi K, Moriwaki K, Yuge O: Perioperative blood transfusion as a prognostic indicator in patients with hepatocellular carcinoma. World J Surg 1999;23:676-680.
23 Kaneda N, Horimi T, Ninomiya M, Nagae S, Mukai K, Takeda I, Shimoyama H, Chohno S, Okabayashi T, Kagawa S, et al: Adverse affect of blood transfusions on survival of patients with gastric cancer. Transfusion 1987; 27:375-377.

24 Blumberg N, Agarwal MM, Chuang C: Relation between recurrence of cancer of the colon and blood transfusion. BMJ 1985;290: 1037-1039.

25 Foster RS, Costanza MC, Foster JC, Wanner $\mathrm{MC}$, Foster CB: Adverse relationship between blood transfusions and survival after colectomy for colon cancer. Cancer 1985;55: 1195-1201.

26 Hyman NH, Foster JC, DeMeules JE, Costanza MC: Blood transfusion and survival after lung cancer resection. Am J Surg 1985;149: 502-507.

27 Rosenberg SA, Seipp CA, White DE, Wesley $\mathrm{R}$ : Perioperative blood transfusions are associated with increased rates of recurrence and decreased survival in patients with highgrade soft-tissue sarcomas of the extremities. J Clin Oncol 1985;3:698-709.

28 Stephenson KR, Steinberg SM, Hughes KS, et al: Perioperative blood transfusion are associated with decreased time to recurrence and decreased survival after resection of colorectal liver metastased. Ann Surg 1988;208: 679-687.

-29 Younes RN, Rogatko A, Brennan MF: The influence of intraoperative hypotension and perioperative blood transfusion on diseasefree survival in patients with complete resection of colorectal liver metastases. Ann Surg 1991;214:107-113.

30 Man K, Fan ST, Ng IO, et al: Prospective evaluation of Pringle maneuver in hepatectomy for liver tumors by a randomized study. Ann Surg 1997;226:704-711.

- 31 Melendez JA, Arslan V, Fischer ME, et al: Perioperative outcomes of major hepatic resections under low central venous pressure anesthesia: blood loss, blood transfusion, and the risk of postoperative renal dysfunction. J Am Coll Surg 1998;187:620-625.

32 Chan AC, Blumgart LH, Wuest DL, et al: Perioperative outcomes of major hepatic resections under low central venous pressure anesthesia: blood loss, blood transfusion, and the risk of postoperative renal dysfunction. Am J Surg 1998;175:461-465. 
-33 Johnson LB, Plotkin JS, Kuo PC: Reduced transfusion requirements during major hepatic resection with use of intraoperative isovolemic hemodilution. Am J Surg 1998; 176:608-611.

34 Ghio M, Contini P, Mazzei C, et al: Soluble HLA class I, HLA class II and Fas ligand in blood components: a possible key to explain the immunomodulatory effects of allogeneic blood transfusions. Blood 1999;93:17701777.

35 Meryman HT, Hornblower M: The preparation of red cells depleted of leukocytes: review and evaluation. Transfusion 1986;26: 101-106.

>36 Snyder EL: Prevention of HLA alloimmunization: role of leukocyte depletion and UV-B irradiation. Yale J Biol Med 1990;63:419427.

37 Yamamoto J, Kosuge T, Takayama T, et al: Perioperative blood transfusion promotes recurrence of hepatocellular carcinoma after hepatectomy. Surgery 1994;115:303-309.

-38 Nagasue N, Ono T, Kohno H, El-Assal ON, Taniura H, Uchida M: Prognostic factors and survival after hepatic resection for hepatocellular carcinoma without cirrhosis. Br J Surg 2001;88:515-522.
39 Gozetti G, Mazziotti A, Grazi GL, Jovine E, Galluci A, Gruttadauria S, Frena A, Morganti M, Ercolani G, Masetti M, et al: Liver resection without blood transfusion. Br J Surg 1995;82:1105-1110.

40 Makino Y, Yamanoi A, Kimoto T, Nazmy ElAssal O, Kohno H, Nagasue N: The influence of perioperative blood transfusion on intrahepatic recurrence after curative resection of hepatocellular carcinoma. Am J Gastroenterology 2000;95:1294-1300.

41 Nagino M, Kamiya J, Arai T, Nishio H, Ebata T, Nimura Y: One hundred consecutive hepatobiliary resections for biliary hilar malignancy: preoperative blood donation, blood loss, transfusion, and outcome. Surgery 2005; 137:148-155.

42 Liu CL, Fan ST, Lo CM, Tso WK, Lam CM, Wong J: Improved operative and survival outcomes of surgical treatment for hilar cholangiocarcinoma. Br J Surg 2006;93: 1488-1494.

43 McLellan SA, Walsh TS, McClelland DBL: Should we demand fresh red blood cells for perioperative and critically ill patients? Br J Anaesth 2002;44:537-540.

44 Messana I, Ferroni L, Misiti F, et al: Blood bank conditions and RBCs: the progressive loss of metabolic modulation. Transfusion 2000;40:353-360.
45 Cunningham J, Fong Y, Shriver C, Melendez J, Mar WL, Blumgart LH: One hundred consecutive hepatic resections: blood loss, transfusion and operative technique. Arch Surg 1994;129:1050-1056.

46 Chan ACW, Blumgart LH, Wuest DL, Melendez JA, Fong Y: Use of preoperative autologous blood donation in liver resections for colorectal metastases. Am J Surg 1998; 175:461-465.

47 Kajikawa M, Nonami T, Kurokawa T, Hashimoto S, Harada A, Nakao A, et al: Autologous blood transfusion for hepatectomy in patients with cirrhosis and hepatocellular carcinoma: use of recombinant human erythropoietin. Surgery 1994;115:727-734.

48 Sejourne P, Poirier A, Meakins JL, Chamieh F, Smadja C, Grange D, et al: Effect of hemodilution on transfusion requirements in liver resection. Lancet 1989;315:1380-1382.

49 Zulim RA, Rocco M, Goodnight JE, Smith GJ, Krag DN, Schneider PD: Intraoperative autotransfusion in hepatic resection for malignancy: is it safe? Arch Surg 1993;128:206211.

50 Fujimoto J, Okamoto E, Yamanaka N, Oriyama T, Furikawa E, et al: Efficacy of autotransfusion in hepatectomy for hepatocellular carcinoma. Arch Surg 1993;128:10651069. 